Article

\title{
A Galvanic Coupling Method for Assessing Hydration Rates
}

\author{
Clement Ogugua Asogwa *, Stephen F. Collins, Patrick Mclaughlin and Daniel T.H. Lai \\ College of Engineering \& Science, Victoria University, Melbourne, VIC 8001, Australia; \\ stephen.collins@vu.edu.au (S.F.C.); patrick.mclaughlin@vu.edu.au (P.M.); daniel.lai@vu.edu.au (D.T.H.L.) \\ * Correspondence: clement.asogwa@live.vu.edu.au; Tel.: +61-3-9919-5047 \\ Academic Editors: Enzo Pasquale Scilingo and Gaetano Valenza \\ Received: 30 May 2016; Accepted: 1 July 2016; Published: 13 July 2016
}

\begin{abstract}
Recent advances in biomedical sensors, data acquisition techniques, microelectronics and wireless communication systems opened up the use of wearable technology for ehealth monitoring. We introduce a galvanic coupled intrabody communication for monitoring human body hydration. Studies in hydration provide the information necessary for understanding the desired fluid levels for optimal performance of the body's physiological and metabolic processes during exercise and activities of daily living. Current measurement techniques are mostly suitable for laboratory purposes due to their complexity and technical requirements. Less technical methods such as urine color observation and skin turgor testing are subjective and cannot be integrated into a wearable device. Bioelectrical impedance methods are popular but mostly used for estimating total body water with limited accuracy and sensitive to $800 \mathrm{~mL}-1000 \mathrm{~mL}$ change in body fluid levels. We introduce a non-intrusive and simple method of tracking hydration rates that can detect up to $1.30 \mathrm{~dB}$ reduction in attenuation when as little as $100 \mathrm{~mL}$ of water is consumed. Our results show that galvanic coupled intrabody signal propagation can provide qualitative hydration and dehydration rates in line with changes in an individual's urine specific gravity and body mass. The real-time changes in galvanic coupled intrabody signal attenuation can be integrated into wearable electronic devices to evaluate body fluid levels on a particular area of interest and can aid diagnosis and treatment of fluid disorders such as lymphoedema.
\end{abstract}

Keywords: galvanic coupling; signal attenuation; hydration rates; body fluid level

\section{Introduction}

Assessment of human body composition is fundamental to the understanding of body physiological and metabolic processes. Body fluid contributes up to 60 percent of the mass of the human body. The body's fluid state is affected by both endogenous processes, such as body metabolism, and exogenous factors such as climatic changes, exercise, disease, and diet. Investigations into hydration are required because they help identify or quantify ill-health and understanding poor exercise performance. Consequences of excessive fluid losses or inadequate fluid intake can include hypohydration, urinary infections, reduction in cognitive function, reduction of cellular metabolism and mortality [1]. The body fluid shifts between the intracellular and the extracellular tissues to maintain water balance. This movement follows an osmotic gradient in order to ensure that optimal concentrations of electrolytes and non-electrolytes are maintained in the cells, tissues, plasma, and interstitial fluid. Two adverse conditions can be identified: hyperhydration, in which there is excess water in the body, and hypohydration or dehydration, when there is less than the normal amount of water to meet the body's requirement [1] and accurate and easy estimates of hydration levels with cost effective technology are essential to policy makers in setting public health priorities [2], for doctors and clinicians to classify body fluid and cell mass conditions of healthy persons and patients with certain 
diseases [3] and for individuals, especially the elderly who are at higher risk of dehydration $[3,4]$. Further research evidence on the elderly showed that older people who were dehydrated at admission were more likely to die than their counterparts [5].

An electrical signal passing through the human body is strongly affected by the size of the tissue, available fluid and its dielectric properties. Tissues have a high ability to store electrical energy. High frequencies are affected by human body antenna effects and possible radiation. Our frequency range lies between $800 \mathrm{kHz}$ and $1.3 \mathrm{MHz}$, which lies within the $\beta$ dispersion region that is related to the cellular structure of biological materials [6] and can penetrate into the extracellular and intracellular tissue spaces. This also falls within the frequency range $(5-1000 \mathrm{kHz})$ used for whole-body fluid analysis with bioimpedance spectroscopy method [7]. The electrical conduction at this frequency is affected by the amount of water solute available in the tissue spaces. Loss of body fluid, for example, during exercise could cause up to $6 \%$ increase in muscle impedance [8]. Thus, by coupling a low frequency electrical signal galvanically on the body, the signal passing through the tissue will vary in attenuation to the changes in the water level. Consequently, the attenuation (negative gain) of the signal amplitude will depend on the composition of the tissue in terms of the amount of water present at the time, the tissue muscle-fat ratio and the input signal frequency. External factors such as the type of electrode, the distance between the connecting electrodes and environmental conditions can be experimentally controlled. Similarly, signal changes due to the effects of limbs around joints [9] can be minimised by avoiding measurement on joint areas.

Techniques for assessing hydration include intrusive and non-intrusive methods. The intrusive method requires intravenous access to the body and is usually performed by trained personnel such as technicians, doctors or nurses. This system requires in vivo access and testing of the blood and is regarded as a later indicator of dehydration rather than a warning system that informs a quick preventative measure [10]. Physical signs such as urine color observation, urine specific gravity test, and body weight changes are some examples of non-intrusive methods for assessing human body hydration [11]. This method gives oversimplified results and poorly sensitive to changes in dehydration [12]. Wearable electronics that measure perspiration metabolites [13] can only estimate the physiological state of an individual's body fluid level under sweat and not without sweat secretion. Moreover, these techniques can not be used to target fluid disorder on a specific part of the body. The purpose of this work is to introduce a galvanic coupled signal propagation method for assessing hydration rates that can also be used for assessing fluid changes on a particular area of the body. Our results are comparable to previous methods, but present an easier wearable alternative to hydration. We argue that undertaking a composite testing of our proposed system alongside known urinary markers of dehydration is vital to validating our proposed idea. This paper is organised are follows: Section 2 details the modification of our previous circuit model. Section 3 is our methodology and Section 4 is the results. This is followed by discussion in Section 5 and conclusion in Section 6.

\section{Modification on Previous Circuit Model}

Our group developed a human body circuit model [14], which was later improved by introducing a dynamic tissue impedance $Z_{F}(t)$. We defined hydration as the process of gaining tissue fluid and proposed in [15] a circuit model of real time human body hydration with time variable fluid impedance (Figure 1), in which $Z_{E S}$ is the impedance of the contact interface to the body at the transmitter and the receiver nodes, $Z_{T}$ corresponds to the transverse impedance, while $Z_{b}$ is the cross impedance. $V_{i}$ is the transmit voltage, while $V_{0}$ is the output voltage at the receiver end with load $R_{l}$. $Z_{L}$ is the longitudinal impedance of the transmission path consisting of the skin, fat, muscle, and bone, body fluid, cortical bone and bone marrow. We defined the variable impedance due to hydration as:

$$
Z_{F}(t)=Z_{f 0}-Z_{w}\left(1-e^{-\frac{t}{\tau}}\right)[15],
$$

where $t$ is the time for the change in impedance to occur, $Z_{f 0}$ is the impedance at time $t=0$ just before hydration begins, $Z_{w}$ is the impedance resulting from the water consumed and the ratio $\frac{t}{\tau}$ is a 
characteristic that predicts the rate of hydration. $\tau$ is the time constant that characterises the metabolic process of a particular individual. We found that given an initial fluid volume $V_{i b}$ before hydration and $V_{w}$ amount of fluid consumed, the body will hydrate to a fluid volume $V_{b}$ given as:

$$
V_{b}=V_{i b}+V_{w} e^{\frac{t}{\tau}} ; t=0 ; V_{b}=V_{i b},
$$

and would reach the state of water balance at time $t_{f}$.

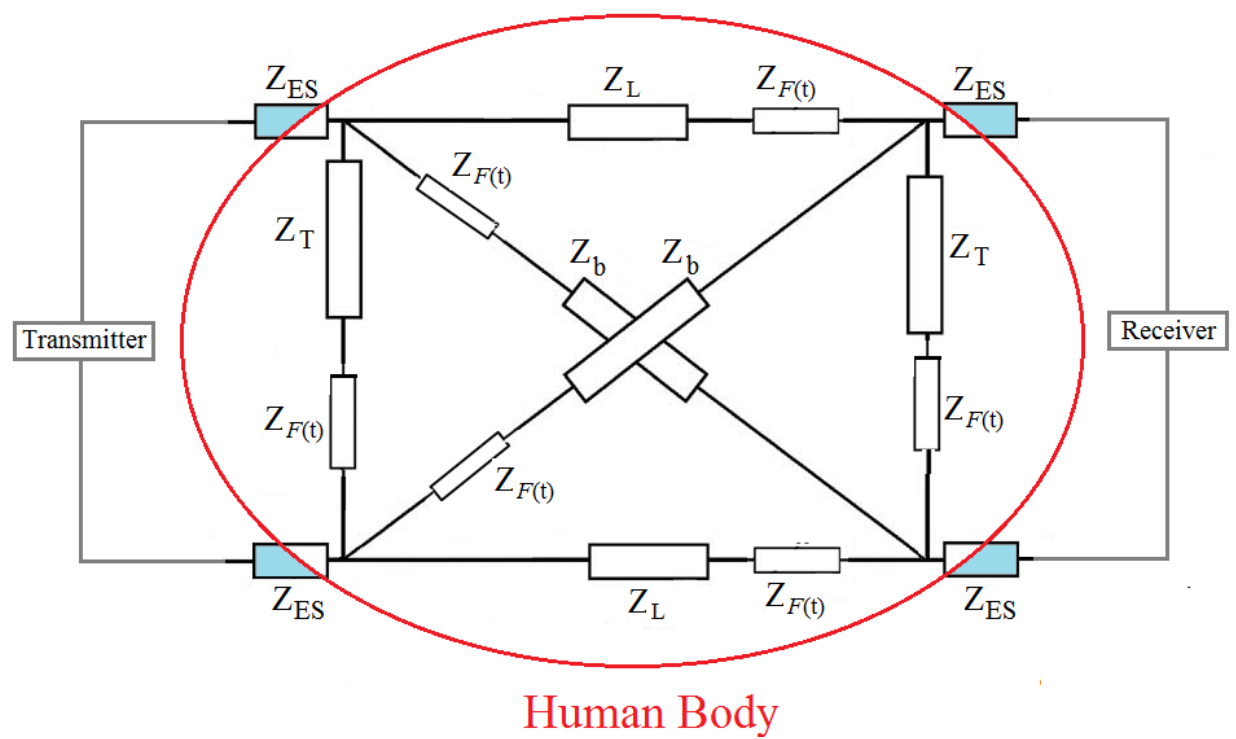

Figure 1. Circuit diagram of galvanic coupled intrabody signal with variable impedance component from variable changes in human body fluid [15], Copyright 2016, IEEE.

Based on this, we propose that the increase in the volume of body fluid, as hydration occurs, increases the volume of tissue fluid which will result in a gain in body weight by an amount equivalent to

$$
w t_{g}=V_{w} e^{\frac{t}{\tau}}
$$

where $w t_{g}$ is gain in weight, since short term changes in body weight can be attributed to loss or gain of body water and $1 \mathrm{~mL}$ of water has a mass of one gram [16]. By representing the anthropometric parameter contributing to the longitudinal impedance between the transmitter and the receiver electrode pairs by the cross-sectional area of the muscle-fat, $\theta$, as a ratio. We have

$$
\theta=\frac{A_{m}}{A_{f}}
$$

where $A_{m}$ and $A_{f}$ are the cross-sectional areas of muscle and fat, respectively, to the distance between the transmitter and receiver electrode pairs. We set $0<\theta<1$-if we assume high $\theta$ corresponded to low fat index (low BMI) and low $\theta$ corresponded to high fat index (high BMI). BMI by definition is body weight $(w t)$ divided by square of height $\left(h^{2}\right)$, unit is $\left(\mathrm{kg} / \mathrm{m}^{2}\right)$

$$
B M I=\frac{w t}{h^{2}} .
$$

Assuming no change in height, since all experimental protocols and measurements were completed within $14 \mathrm{~h}$ for each participating adult, then,

$$
w t \propto B M I,
$$


and a change in $w t$ due to hydration or dehydration will also result in a change in $B M I$,

$$
\Delta w t \propto \Delta B M I .
$$

Therefore, $\theta$ can be defined in terms of the changes in real body weight. We know from $[17,18]$ that short term changes in body mass are associated with changes in human body hydration state given by Equation (3). $w t_{g}=\Delta w t$. If we assume a BMI mainly due to fat mass, then $\theta$ is inversely proportional to BMI. By these definitions:

$$
\Delta w t \propto \Delta \frac{1}{\theta}
$$

or

$$
\Delta w t \theta=k
$$

Similarly,

$$
\Delta w t \propto \Delta G
$$

where $\Delta G$ is the change in gain (negative attenuation) of the electrical signal as a result of the change in the body hydration state, measured in $\mathrm{dB} /$ minute. $\Delta w t$ is related to $\theta$ by a proportionality constant $k$. If $\Delta w t$ and $\theta$ are biological constants, then the constant of proportionality $k$ which affects the biological behaviour of the body under hydration is also biological and, from Equations (9) and (10), $k$ is a metabolic process equivalent to $\tau$, which, by Mifflin-St. Jeor equation [19], is related to resting metabolic rate (RMR). A dynamic change in the impedance caused by a change in the human body hydration state would result in a change of the impedance of $Z_{T}, Z_{L}$, and $Z_{b}$ as following:

$$
\begin{aligned}
& \dot{Z}_{T}=Z_{T}+Z_{F}(t), \\
& \dot{Z}_{L}=Z_{L}+Z_{F}(t), \\
& \dot{Z}_{b}=Z_{b}+Z_{F}(t) .
\end{aligned}
$$

Similarly, $G(f ; t ; w t ; \tau)$.

Thus, the signal attenuation $G(f, t, w t, \tau)$ of a galvanically coupled circuit passing through the human body can be expressed in terms of frequency $f$, time $t$, change in body weight $w t$, and a time-dependent constant $\tau$ related to RMR [19]. This expression is similar to our previous expression of the gain $G$ of a galvanic coupled circuit (Figure 1), with the transfer function as shown in [15]. We argued that if Equation (5) defined BMI in terms of excess body fat, then individuals with high BMI will, on average, have a lower hydration rates, will keep water longer in the body, and hence take longer to urinate, and the reverse is true if defined in terms of excess muscle mass. We shall use this relationship to empirically determine the attenuation per unit volume of water consumed in Section 3 .

\section{Methodology}

\subsection{Equipment}

The measurement set up is as shown in Figure 2. We used a hand held refractometer, URICON-NE, Cat. No. 2722 with measurement uncertainty of 0.001 from ATAGO Co., Ltd.,Itabashi-ku, Tokyo, Japan to measure the urine specific gravity of the urine samples provided by the participants. Urine specific gravity (SPG) measures the ratio of the density of urine relative to the density of pure water. A specific gravity greater than one means the fluid is denser than water [20]. Urine specific gravity measurements usually range from 1.002 to 1.030 . Minimal dehydration ranges from 1.010 to 1.020 with increasing severity of dehydration from 1.020 and upwards. A specific gravity of 1.030 and upwards is regarded as highly severe and values below 1.010 are classified as hyperhydration [20-22]. Other factors such as glucose level and drug use that may affect specific gravity readings were countered by ensuring 
that participants' diets prior to experiment were controlled and exclusive of supplements, were not taking medical drugs, and are healthy. Moreover, the experiment started after an overnight 12-h fast. We also set the specific gravity measurements as a second test for determining individual hydration level and used it in conjunction with body mass changes for our investigation. We used Hanna digital thermometer model number HI-98509 (Manufactured by Hanna Instruments, Woonsocket, RI, USA,) to measure the temperature of the urine samples. We measured the urine specific gravity of the urine samples at the required temperature of $20.0^{\circ} \mathrm{C}$. A mini Pro Vector Network Analyser (VNA), frequency range $100 \mathrm{kHz}$ to $200 \mathrm{MHz}$, manufactured by Mini Radio Solutions, Poland, baluns (Coaxial RF transformers, FTB-1-1+, turns ratio of one, manufactured by Mini-Circuits (Brooklyn, NY, USA), and frequency range $0.2-500 \mathrm{MHz}$ ), and round pre-gelled self-adhesive $\mathrm{Ag} / \mathrm{AgCl}$ snap single electrodes ( $1 \mathrm{~cm}$ diameter, manufactured by Noraxon (Noraxon Inc.,Scottsdale, AZ, USA) were used with $20 \mathrm{~cm}$ as the separation distance between the transmit and receive electrodes [23] to measure the signal attenuation. The Noraxon self-adhesive Silver/Silver-Chloride electrodes ( $\mathrm{Ag} / \mathrm{AgCl})$ are preferred because they are designed for both research and clinical use, contain hypoallergenic gel, can be used for two hours of measurement, and reduce the effects of motion artifacts and refection compared to polarizable electrodes. The baluns are used to electrically isolate the two ports of the VNA to ensure the return current does not make a loop through the common ground of the two ports. An off-the-shelf electronic WeightWatchers weight tracking \& body composition monitor model number WW125A (made in China) with measurement uncertainty $\pm 50 \mathrm{~g}$ was used to measure changes in body mass of the subjects. Subjects wore light clothing and were barefoot. Subject height was measured to the nearest $0.5 \mathrm{~cm}$ measured against the wall bare footed and heels together with buttocks, shoulders, and head touching the vertical wall surface and clear horizontal marking sighted. Participants were given time to read and understand the experiment procedures and their consents were obtained in line with the approved procedures of the Victoria University Human Research Ethics Committee.

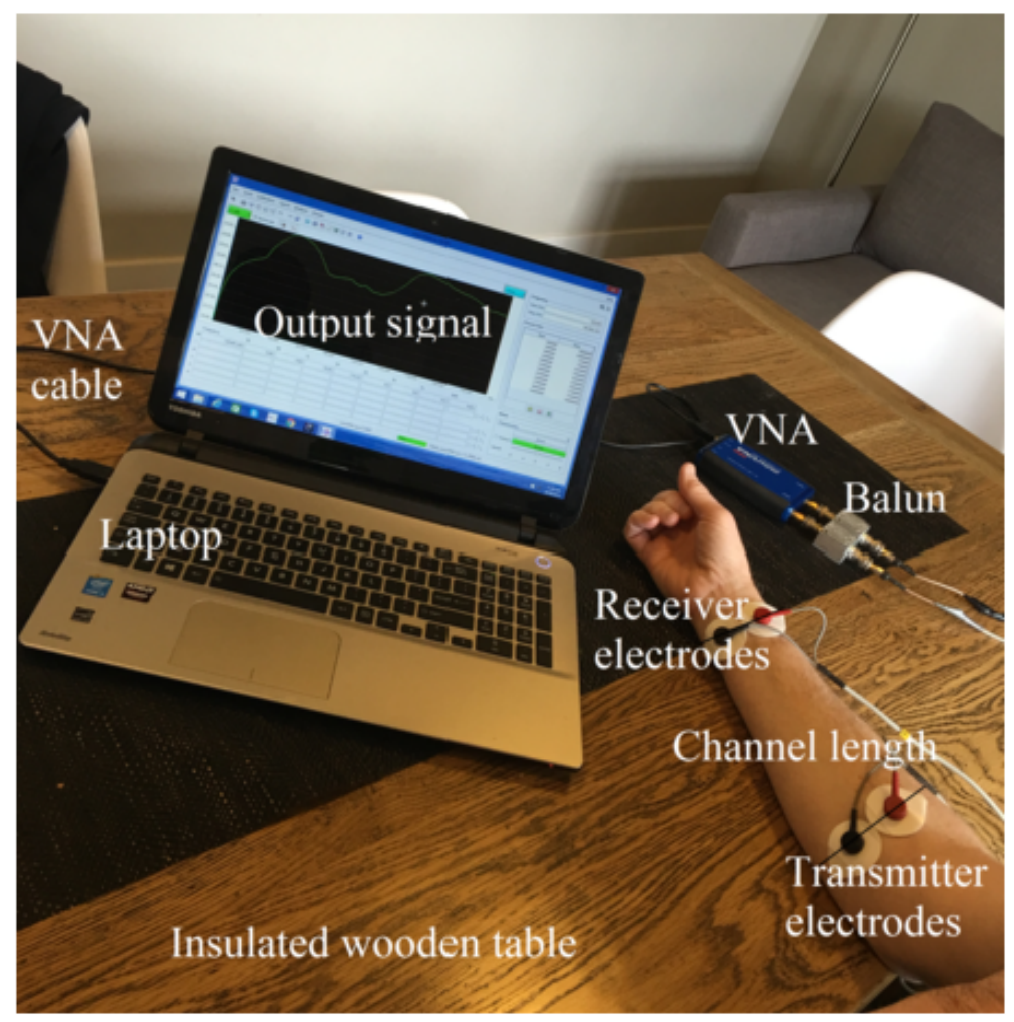

Figure 2. Intrabody signal propagation connected galvanically to measure signal attenuation after 600 $\mathrm{mL}$ fluid intake and after urinating on 12 male and eight female healthy adults. 


\subsection{Experiment I: Hydration Testing}

Twenty subjects consisting of 12 males and eight females participated in this experiment. We defined two experimental protocols in this test. First, the hydration measurement protocol, which is preceded by fluid abstinence after supper (latest $10.00 \mathrm{pm}$ ) until $10 \mathrm{a} . \mathrm{m}$. to induce dehydration. We measured the level of dehydration on each subject by testing the specific gravity of urine sample 1 collected prior to the start of the experiment. In addition, $600 \mathrm{~mL}$ of water was given to each subject to drink and the rate of hydration measured $5 \mathrm{~min}$ after intake-this is because water appears in plasma and blood cells within $5 \mathrm{~min}$ after consumption [24]. All of the participants sat on a plastic chair and were told not to move as much as humanly possible. The measured arm rested on a wooden table (Figure 2) was insulated to ensure no current leakage and to ensure movement artefacts were minimized. In the second protocol, we determined the rate of dehydration after the subjects had urinated following the consumption of $600 \mathrm{~mL}$ of water. We also recorded the elapsed time to produce urine by each subject. We established the pre and post hydration states of each subject by testing the individual urine specific gravity of both urine samples 1 and 2 with the hand held refractometer. We observed the urine colour changes and took measurements of the body mass differences with the electronic floor scale. The body mass of each participant was measured as $W_{0}$ before drinking, $W_{1}$ immediately after drinking and $W_{2}$ after urinating. We used a volumetric cylinder to measure the volume of urine samples produced after the $600 \mathrm{~mL}$ of water intake. Both the hydration and dehydration measurements were measured by taking five measurements of signal attenuation at $5 \mathrm{~min}$ intervals, and the average was used. The change in post drink weight and post urination weight was observed and recorded against the refractometer readings and the changes in signal attenuation. Subjects were not permitted to do rigorous exercises during the intervals throughout the period of the experiment, and all measurements were carried out at $10.00 \mathrm{am}$ and average room temperature of $25 \pm 0.1{ }^{\circ} \mathrm{C}$ was maintained throughout. Interference and background noise was minimised by switching off electronic devices and wireless systems around the vicinity. We also isolated communication cables away from power packs and the laptop operated at battery mode. All measurements followed the approved procedures of the Victoria University Human Research Ethics Committee, approval number HRE 14-122.

\subsection{Experiment II: Sensitivity Test By Empirical Measurement}

Three subjects consented to participate further in this experiment. The experiment was performed on three random days and completed in three weeks. We set the control for the sensitivity test as the average value of the signal attenuation measured for a given period of time before fluid intake. We define our sensitivity as the smallest amount of water consumed that causes a galvanic coupled intrabody signal to amplify beyond the control level after fluid intake. Both the control and the sensitivity test were performed the same day and under the same condition. To measure this, we extended the pre-drink, post drink and the measurements after urinating to $30 \mathrm{~min}$. This is because we observed in experiment I that, while many subjects indicated hydration within twenty minutes, we want to observe, if there was any evidence of hydration occurring after $20 \mathrm{~min}$. The $30 \mathrm{~min}$ pre-drink measurement was to serve as a baseline or control test. The sensitivity test followed the process narrated in experiment $\mathrm{I}$, with a variation in the amount of water consumed by the subjects ranging from $100 \mathrm{~mL}, 250 \mathrm{~mL}$ to $300 \mathrm{~mL}$ on each day of the experiment. The result is reported in Section 4 for both hydration and dehydration stages.

\subsection{Experiment III: Sensitivity Test By Simulation}

Experiment II showed the minimum amount of water to be detected as $100 \mathrm{~mL}$. We test this theoretically using our circuit model Figure 1 with the same parameters for the anthropometric measurements of the arm [25] in which a $50 \mathrm{~mm}$ arm radius, has the thickness of body fluid layer as $23 \mathrm{~mm}$ estimated from [26,27]. After consuming $100 \mathrm{~mL}$ of water, the maximum gain will occur 
when all the water consumed is retained within the $20 \mathrm{~cm}$ channel length. This will increase the fluid layer thickness to $26 \mathrm{~mm}$, so that for a $100 \mathrm{~mL}$ fluid in intake, $w t_{g}=0.1 \mathrm{~kg}$. Using the transfer function of $G$ derived in [15]. We have the sensitivity after consumption of $100 \mathrm{~mL}$ of water maximum signal gain occurring when the $100 \mathrm{~mL}$ are absorbed within the $20 \mathrm{~cm}$ channel length.

\section{Results}

Table 1 presents the data from the twenty subjects. Firstly, the weighing scale measurements differed slightly from expected results after $600 \mathrm{~mL}$ of fluid intake, i.e., $W_{1}-W_{0} \neq 600 \mathrm{~g} \pm$ (uncertainty in measurement ) in some cases. However, the change in weight after urinating, $W_{2}-W_{1}$, corresponded to the volume of urine produced for most of the subjects. Similarly, urine specific gravity (SPG) measurement decreased from SPG1, measurement after fasting, to SPG2, measurement after fluid intake, as expected. This means that the fluid intake produced rehydration and lowering of the urine density. In a healthy person, the kidney regulates water balance by conserving water or getting rid of excess water relative to the requirement for a healthy water balance [28]. When the amount of water consumed is large enough to reduce the concentration of blood plasma, a urine more dilute than blood plasma is produced; on the other hand, when the available water is too small to dilute the blood plasma concentration, a more concentrated urine than the blood plasma is produced [29]. Higher specific gravity values indicates higher dehydration. These instances are reflected in our result. Therefore, we shall match the changes in the urine specific gravity of the subjects with the differences in weight between $W_{2}$ and $W_{0}$, and the measured attenuation after an intrabody signal is transmitted galvanically, as explained in the experiment procedure, for our analysis. The average observation on the elapsed time between fluid intake and urination increases with increase in body mass index.

Table 1. Effect of hydration on body weight and urine specific gravity (SPG) on 20 subjects.

\begin{tabular}{|c|c|c|c|c|c|c|c|c|}
\hline Subject & $\begin{array}{c}\text { BMI } \\
\left(\mathrm{kg} / \mathrm{m}^{2}\right)\end{array}$ & $\begin{array}{c}W_{0} \\
(\mathrm{~kg})\end{array}$ & $\begin{array}{l}W_{1} \\
(\mathrm{~kg})\end{array}$ & $\begin{array}{l}W_{2} \\
(\mathrm{~kg})\end{array}$ & $\begin{array}{l}\text { Volume of } \\
\text { Urine (mL) }\end{array}$ & $\begin{array}{l}\text { Elapsed Time } \\
\text { (Minutes) }\end{array}$ & $\begin{array}{c}\text { SPG1 } \\
\text { before Drink }\end{array}$ & $\begin{array}{c}\text { SPG2 } \\
\text { after Drink }\end{array}$ \\
\hline A & 29.3 & 87.60 & 88.15 & 88.10 & 75 & 118 & 1.021 & 1.018 \\
\hline $\mathrm{B}^{* * *}$ & 20.8 & 56.70 & 57.30 & 57.10 & 190 & 61 & 1.030 & 1.007 \\
\hline C & 24.2 & 72.55 & 73.10 & 72.60 & 250 & 56 & 1.025 & 1.010 \\
\hline$D^{* *}$ & 31.4 & 83.15 & 83.55 & 83.15 & 340 & 76 & 1.016 & 1.010 \\
\hline E & 33.1 & 93.40 & 93.90 & 93.50 & 305 & 111 & 1.017 & 1.008 \\
\hline$F^{*}$ & 28.5 & 75.65 & 76.15 & 75.30 & 360 & 95 & 1.020 & 1.005 \\
\hline$G^{* *}$ & 23.5 & 62.80 & 63.20 & 62.80 & 330 & 60 & 1.016 & 1.010 \\
\hline $\mathrm{H}$ & 31.4 & 101.00 & 101.60 & 101.40 & 150 & 70 & 1.020 & 1.015 \\
\hline I & 26.4 & 81.65 & 82.10 & 81.85 & 220 & 99 & 1.023 & 1.014 \\
\hline $\mathrm{J}$ & 36.5 & 104.25 & 104.75 & 104.35 & 325 & 125 & 1.021 & 1.016 \\
\hline $\mathrm{K}$ & 22.9 & 76.00 & 76.55 & 76.30 & 100 & 70 & 1.019 & 1.016 \\
\hline $\mathrm{L}$ & 23.7 & 73.50 & 74.20 & 73.80 & 300 & 51 & 1.020 & 1.007 \\
\hline$M^{* * *}$ & 25.6 & 95.30 & 95.70 & 95.50 & 200 & 60 & 1.031 & 1.007 \\
\hline $\mathrm{N}$ & 25.9 & 78.60 & 79.10 & 78.80 & 175 & 86 & 1.024 & 1.010 \\
\hline $\mathrm{O} *$ & 42.5 & 122.8 & 123.30 & 122.25 & 400 & 155 & 1.011 & 1.010 \\
\hline $\mathrm{P}$ & 24.4 & 64.00 & 64.50 & 63.90 & 250 & 77 & 1.021 & 1.005 \\
\hline Q & 21.9 & 60.30 & 60.75 & 60.50 & 125 & 78 & 1.017 & 1.014 \\
\hline $\mathrm{R}$ & 23.7 & 66.20 & 66.80 & 66.40 & 350 & 93 & 1.017 & 1.004 \\
\hline$S$ & 24.0 & 67.70 & 68.30 & 68.00 & 250 & 62 & 1.023 & 1.006 \\
\hline $\mathrm{T}$ & 26.1 & 92.35 & 92.60 & 92.50 & 175 & 47 & 1.020 & 1.008 \\
\hline
\end{tabular}

Subject specific cases were observed based on the assumption that the water consumed was retained or excreted based on the initial body hydration level and the need to maintain homeostasis water balance [28]. In Case 1 Figure $3, W_{2}<W_{0}=$ Hyper hydration (example, subjects $F$ and $\mathrm{O}$ ). Subjects weighed less than the base line weight after urinating and initial specific gravity is low. Subjects produced the largest volume of urine after the specified drink. This suggests excess water in the subjects before the $600 \mathrm{~mL}$ intake, thus $W_{2}<W_{0}$. Absorption was observed after subjects had urinated. In Case 2 Figure $4, W_{2}=W_{0}=$ Optimal hydration (example, subjects D and G). Here, 
subjects' baseline weight was the same as the weight after urinating, and the subjects produced a large amount of urine. The fluid intake after the state of water balance was reached did not cause immediate hydration; therefore, tissue absorption and de-absorption was not continuous and water intake did not cause significant change in signal attenuation. Fluid abstinence before 10.00 a.m. did not make these groups of subjects dehydrate.
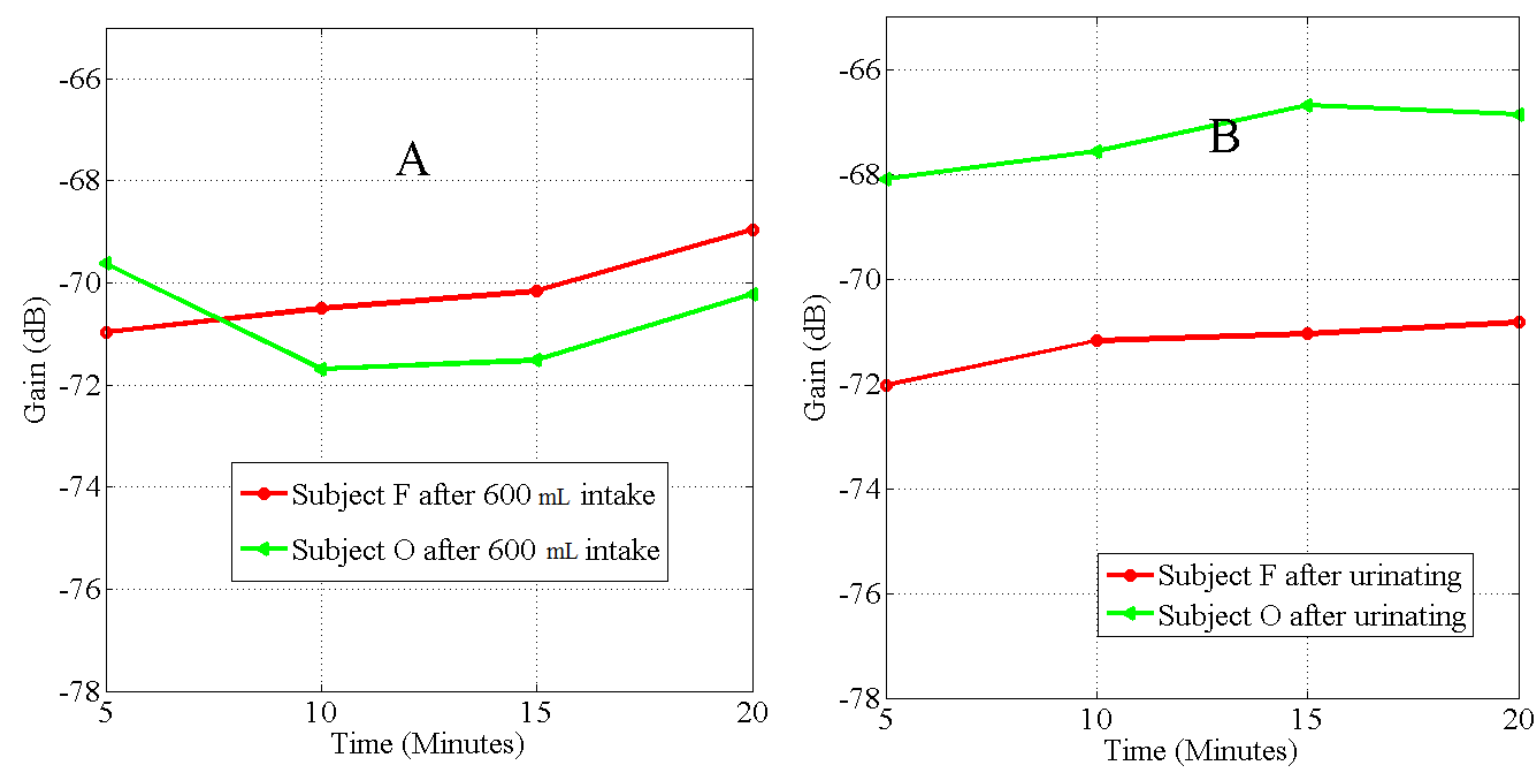

Figure 3. Graph of the rate of hydration (A), and dehydration (B), after $600 \mathrm{~mL}$ fluid intake on subjects $\mathrm{F}$ and $\mathrm{O}$ observed at $1.2 \mathrm{MHz}, W_{2}<W_{0}$. Subjects were hyper hydrated by the protocol.
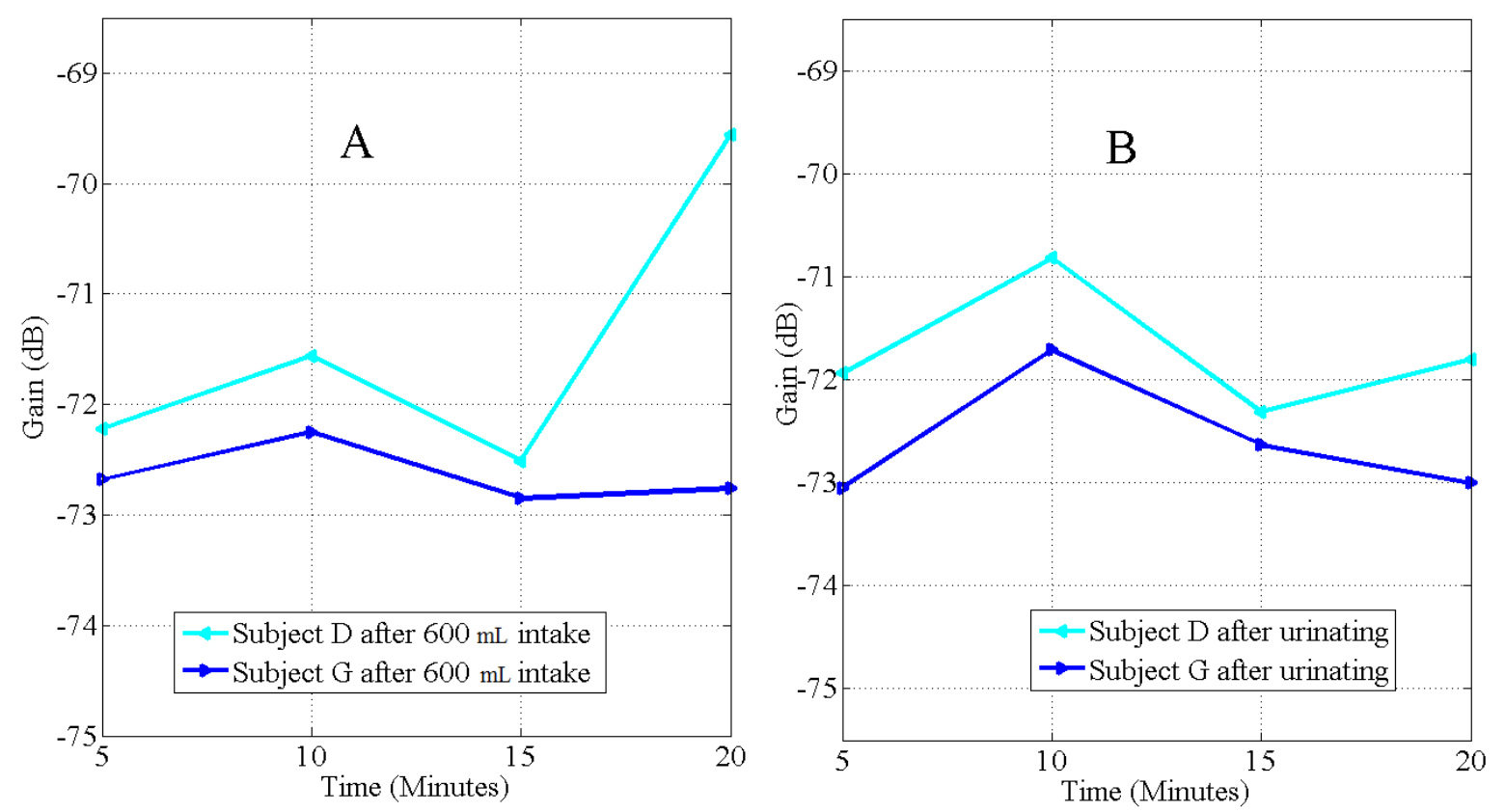

Figure 4. Graph of the rate of hydration (A), and dehydration (B), after $600 \mathrm{~mL}$ of fluid intake on subjects $\mathrm{D}$ and $\mathrm{G}$ at $900 \mathrm{kHz}, W_{2}=W_{0}$. Subjects were normally hydrated by the protocol.

In Case 3 Figure 5, $W_{2}>W_{0}=$ Severe dehydration (example, subjects $B$ and $M$ ). Subjects had urine specific gravity that reflected extreme water loss, and the time taken to urinate was high compared to individual BMI. After urinating, dehydration occurred and was observed at different times. 
The rest of the subjects were grouped as Case 4 Figure $6, W_{2}>W_{0}$, mild dehydration based on the urine specific gravity reading SPG1 measured before fluid intake. Among this group, the maximum rate of hydration was $0.44 \mathrm{~dB} /$ min occurring in subject $\mathrm{N}$, SPG1 $=1.024$, while the minimum rate occurred at $0.02 \mathrm{~dB} / \mathrm{min}$ on subject $\mathrm{Q}, \mathrm{SPG} 1=1.017$. After urination, the maximum rate of dehydration occurred at $0.40 \mathrm{~dB} / \mathrm{min}$ with subject $\mathrm{L}$, $\mathrm{SPG} 1=1.020$, while the minimum rate was $0.11 \mathrm{~dB} / \mathrm{min}$ occurring in subject $\mathrm{C}, \mathrm{SPG} 1=1.025$.

Figure 7 is the graph of the subject's BMI against time taken for individual metabolic process to complete and process urine. The figure shows that BMI is related with the time it takes to process urine and is also related with the rate of hydration and dehydration in accordance with our previous findings [15]. Figure 8 depicts the empirical results of the sensitivity of a galvanic coupled signal to detect hydration due to body fluid intake, while Figure 9 is the simulation result for a $100 \mathrm{~mL}$ maximum fluid absorption with our circuit model.
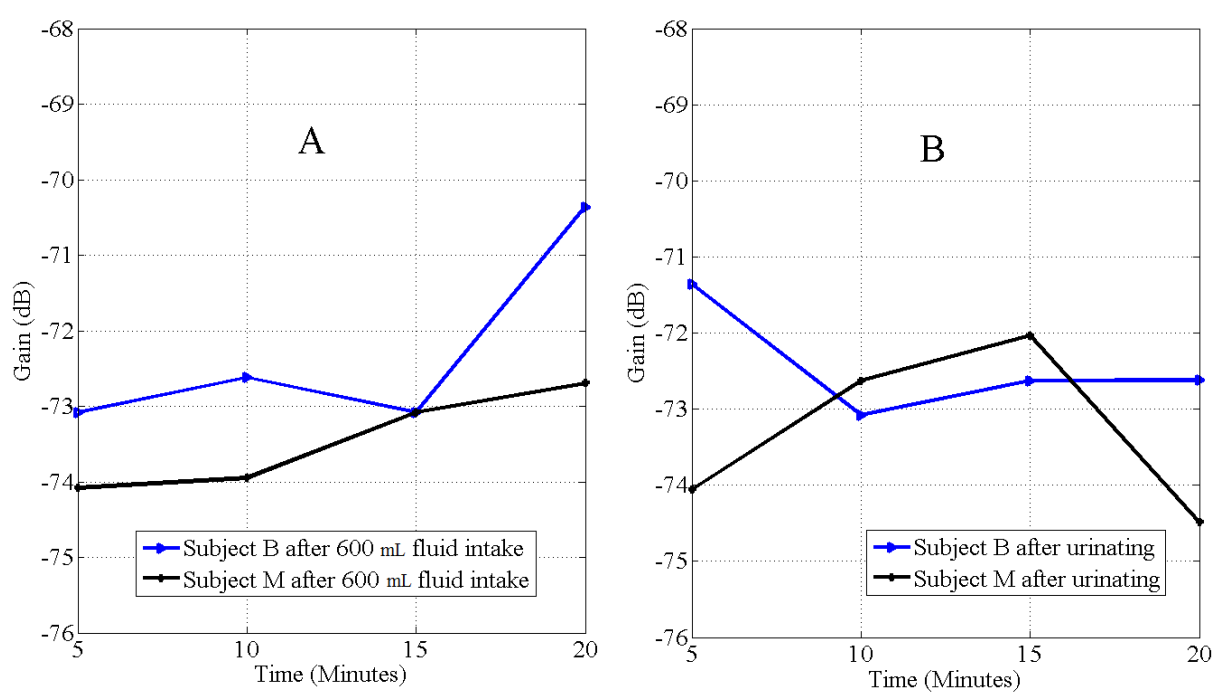

Figure 5. Graph of the rate of hydration (A), and dehydration (B), after $600 \mathrm{~mL}$ of fluid intake on subjects $\mathrm{B}$ and $\mathrm{M}$ observed at $900 \mathrm{kHz}, W_{2}<W_{0}$. The protocol produced severe dehydration on subjects B and M. After urinating, subject B dehydrated and stopped after $10 \mathrm{~min}$, while subject $\mathrm{M}$ started dehydration after $15 \mathrm{~min}$. Both showed longer periods of re-absorption.
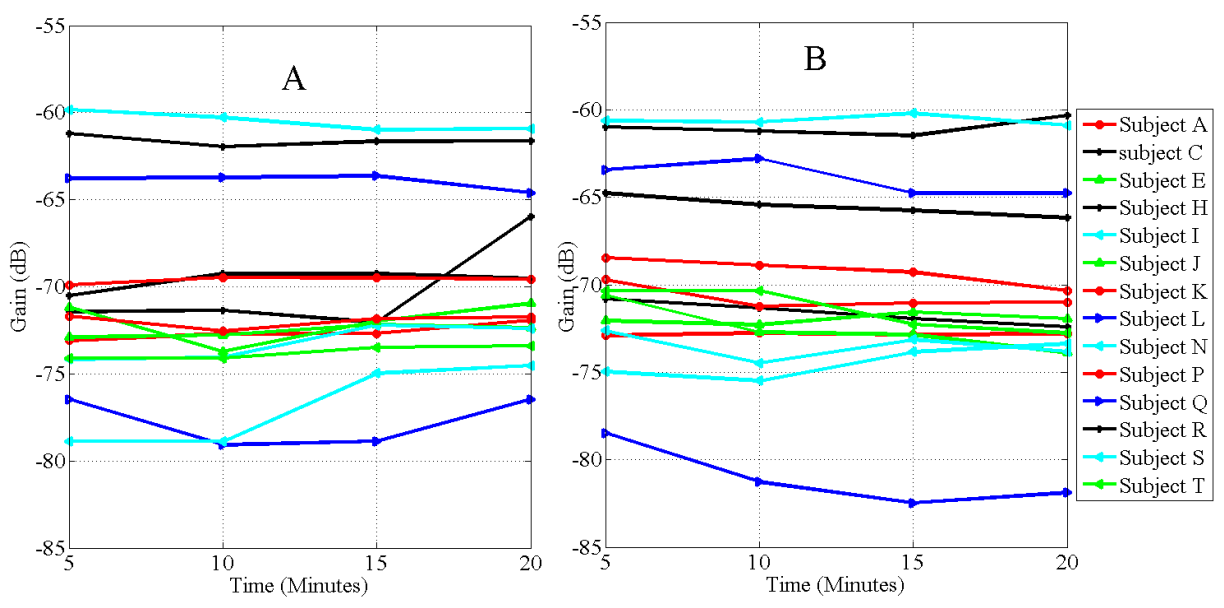

Figure 6. Graph of the rate of hydration (A), and dehydration (B), after $600 \mathrm{~mL}$ of fluid intake on subjects $A, C, E, H, I, J, K, L, N, P, Q, R, S$ and T observed at $900 \mathrm{kHz} . W_{2}<W_{0}$. The protocol produced mild dehydration on subjects. 


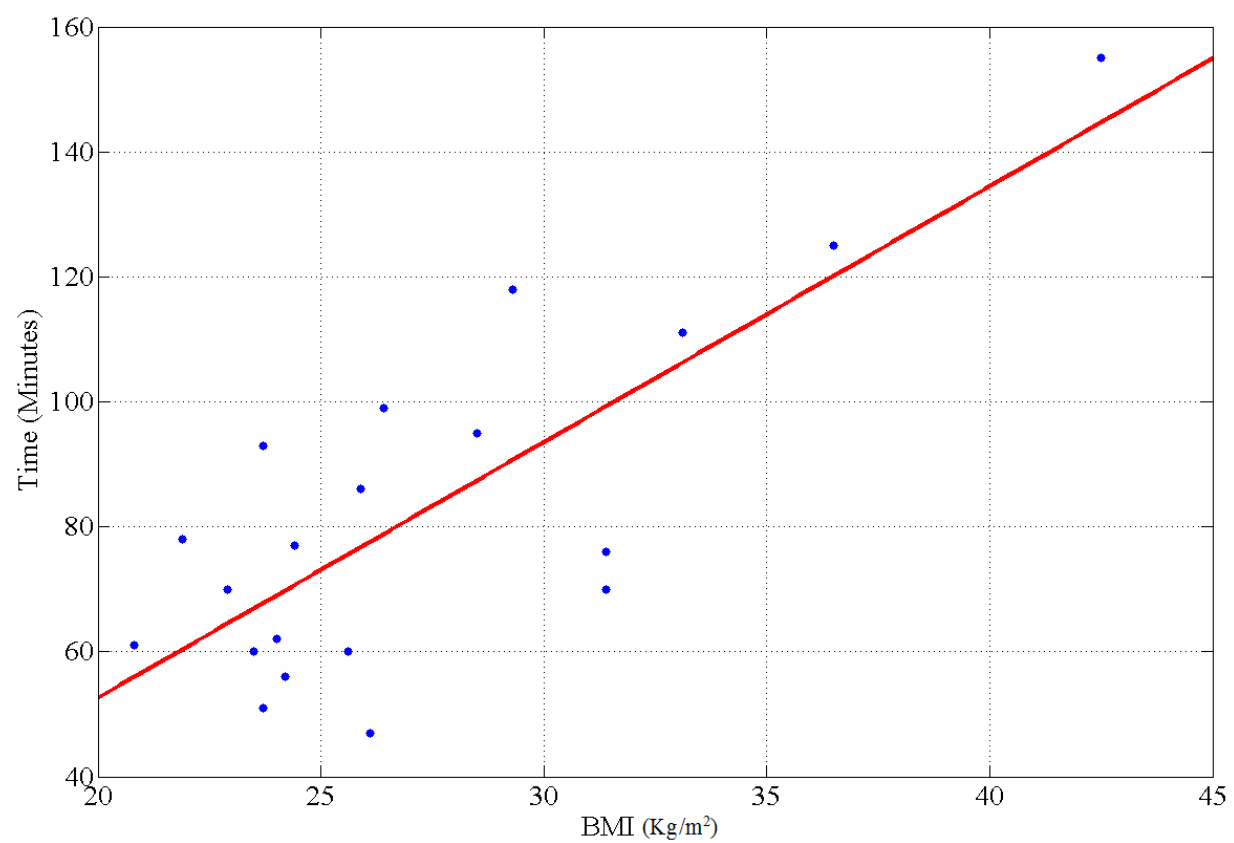

Figure 7. Graph of the relation between subject specific body mass index (BMI) and the time it took to urinate after consuming $600 \mathrm{~mL}$ of water.

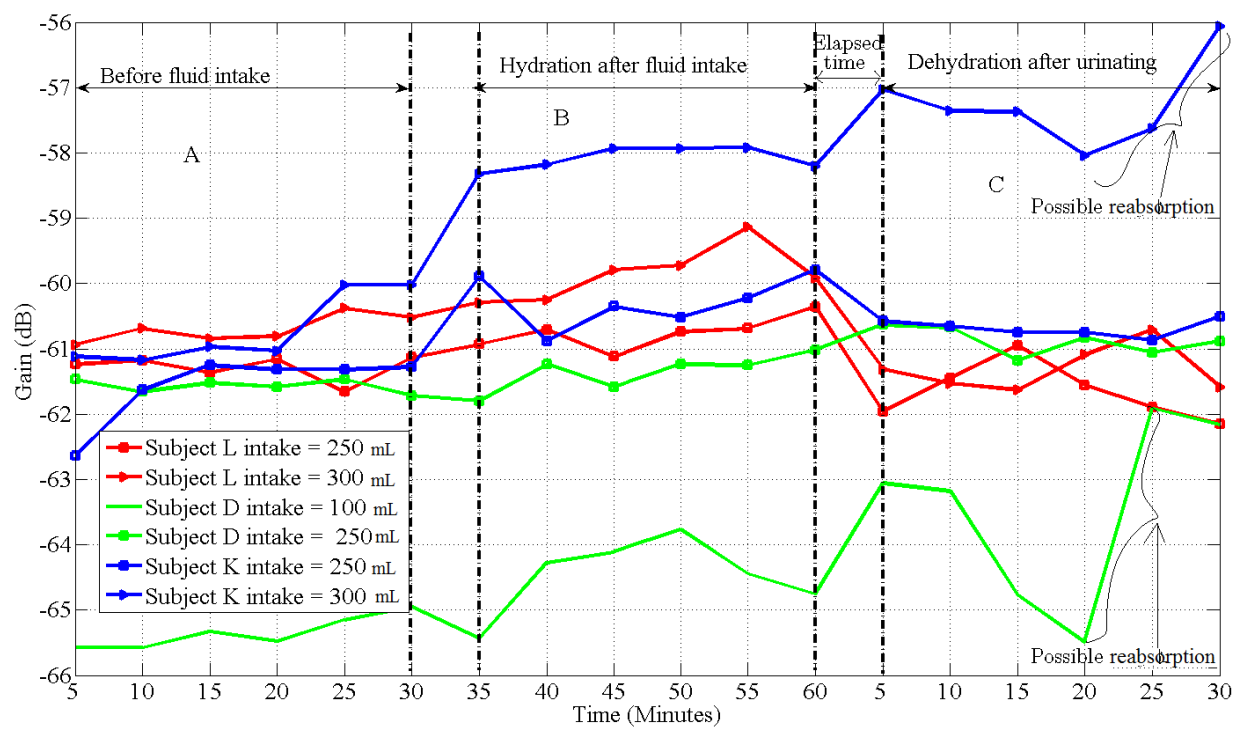

Figure 8. This graph represents the sensitivity test for an intrabody signal measured on three subjects for three random days at $900 \mathrm{kHz}$, before drinking (A), after drinking $100 \mathrm{~mL}, 250 \mathrm{~mL}$ and $300 \mathrm{~mL}$ amounts of water (B), and after urinating (C). From $5 \mathrm{~min}-30 \mathrm{~min}$ is the average attenuation measured before drink. After drinking, the attenuation was measured from 35-60 min. The gap between measurement after drink and urination is a variable time that elapsed before each subject urinates. After urinating, the attenuation was again measured from $5 \mathrm{~min}$ to $30 \mathrm{~min}$. Measurements were taken at $900 \mathrm{kHz}$ and subject specific parameters are: Subject D height $=166 \mathrm{~cm}$ and BMI $=29.83$ on day 1, Subject $\mathrm{K}$ height $=182 \mathrm{~cm}$ and BMI 23.81 on day 2 , and subject $\mathrm{L}$ height $=176 \mathrm{~cm}$ and BMI 23.34 on day 3. 

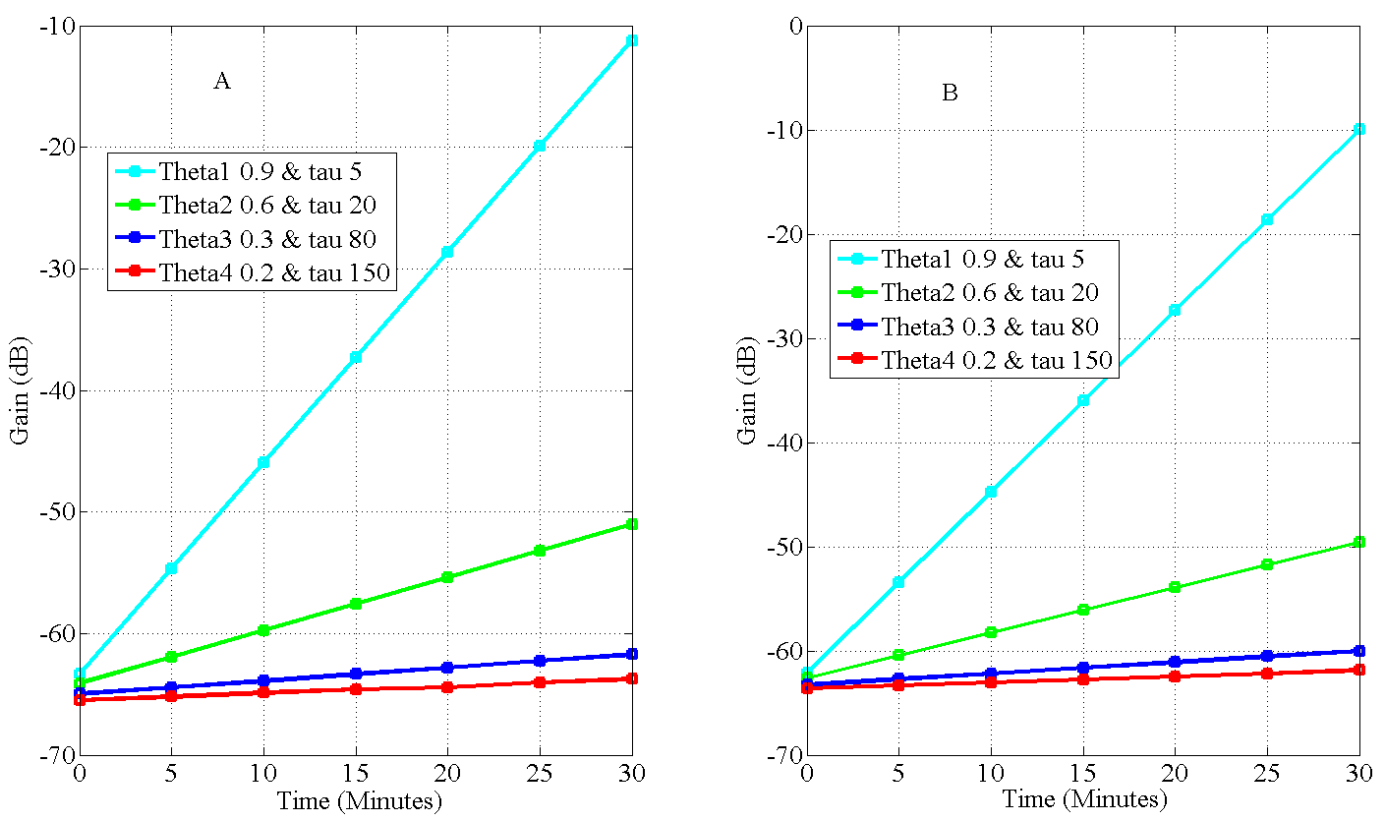

Figure 9. Simulated sensitivity of a galvanic coupled intrabody at $900 \mathrm{kHz}$ at different combinations of $\tau$ and $\theta$. (A) is before $100 \mathrm{~mL}$ fluid intake and thickness $=23 \mathrm{~mm}$, while (B) is after $100 \mathrm{~mL}$ intake, assuming maximum concentration of this amount within $20 \mathrm{~cm}$ inter-electrode distance, fluid thickness $=26 \mathrm{~mm}$. Predicted increase in attenuation is $1.5 \mathrm{~dB}$ for $\tau=20$ and $\theta=0.6$, and $1.70 \mathrm{~dB}$ for $\tau=80$ and $\theta=0.3$ and $1.91 \mathrm{~dB}$ for $\tau=150$ and $\theta=0.2$

Subjects D, K, and L, height $166 \mathrm{~cm}, 182 \mathrm{~cm}$ and $176 \mathrm{~cm}$, respectively, participated in the control and sensitivity tests.

Tables $2-4$ are the control and sensitivity results. The tables show that for the three random days tested, the variation in the subjects' body mass was below $2 \mathrm{~kg}$, and the change in body weight corresponded to the quantity of water consumed by the subjects on each day of the experiment. The weight also decreased after the subjects had urinated and the urine specific gravity dropped after water was consumed.

Table 2. Control and sensitivity test, Day I.

\begin{tabular}{|c|c|c|c|c|c|c|}
\hline \multirow[b]{2}{*}{ Subject } & \multicolumn{5}{|c|}{ Fluid Intake $=100 \mathrm{~mL}$} & \multirow[b]{2}{*}{$\begin{array}{c}\text { SPG2 } \\
\text { after Drink }\end{array}$} \\
\hline & $\begin{array}{c}\text { BMI } \\
\left(\mathrm{kg} / \mathrm{m}^{2}\right)\end{array}$ & $\begin{array}{l}W_{0} \\
(\mathrm{~kg})\end{array}$ & $\begin{array}{l}W_{1} \\
(\mathrm{~kg})\end{array}$ & $\begin{array}{l}W_{2} \\
(\mathrm{~kg})\end{array}$ & $\begin{array}{c}\text { SPG1 } \\
\text { before Drink }\end{array}$ & \\
\hline $\mathrm{D}$ & 29.83 & 82.20 & 82.30 & 82.20 & 1.014 & 1.014 \\
\hline K & 23.58 & 78.10 & 78.20 & 78.20 & 1.022 & 1.021 \\
\hline $\mathrm{L}$ & 23.44 & 72.60 & 72.70 & 72.60 & 1.023 & 1.021 \\
\hline
\end{tabular}

Table 3. Control and sensitivity test, Day II.

\begin{tabular}{|c|c|c|c|c|c|c|}
\hline \multirow[b]{2}{*}{ Subject } & \multicolumn{5}{|c|}{ Fluid Intake $=250 \mathrm{~mL}$} & \multirow[b]{2}{*}{$\begin{array}{c}\text { SPG2 } \\
\text { after Drink }\end{array}$} \\
\hline & $\begin{array}{c}\text { BMI } \\
\left(\mathrm{kg} / \mathrm{m}^{2}\right)\end{array}$ & $\begin{array}{l}W_{0} \\
(\mathbf{k g})\end{array}$ & $\begin{array}{l}W_{1} \\
(\mathrm{~kg})\end{array}$ & $\begin{array}{l}W_{2} \\
(\mathrm{~kg})\end{array}$ & $\begin{array}{c}\text { SPG1 } \\
\text { before Drink }\end{array}$ & \\
\hline $\mathrm{D}$ & 29.65 & 81.70 & 81.90 & 81.80 & 1.016 & 1.012 \\
\hline K & 23.81 & 77.95 & 78.20 & 78.10 & 1.025 & 1.018 \\
\hline $\mathrm{L}$ & 23.27 & 72.10 & 72.40 & 72.20 & 1.021 & 1.010 \\
\hline
\end{tabular}


Table 4. Control and sensitivity test, Day III.

\begin{tabular}{|c|c|c|c|c|c|c|}
\hline \multirow[b]{2}{*}{ Subject } & \multicolumn{5}{|c|}{ Fluid Intake $=300 \mathrm{~mL}$} & \multirow[b]{2}{*}{$\begin{array}{c}\text { SPG2 } \\
\text { after Drink }\end{array}$} \\
\hline & $\begin{array}{c}\text { BMI } \\
\left(\mathrm{kg} / \mathrm{m}^{2}\right)\end{array}$ & $\begin{array}{l}W_{0} \\
(\mathrm{~kg})\end{array}$ & $\begin{array}{l}W_{1} \\
(\mathrm{~kg})\end{array}$ & $\begin{array}{l}W_{2} \\
(\mathrm{~kg})\end{array}$ & $\begin{array}{c}\text { SPG1 } \\
\text { before Drink }\end{array}$ & \\
\hline $\mathrm{D}$ & 29.90 & 82.40 & 82.70 & 82.55 & 1.014 & 1.014 \\
\hline $\mathrm{K}$ & 23.81 & 78.00 & 78.20 & 78.10 & 1.023 & 1.021 \\
\hline $\mathrm{L}$ & 23.34 & 72.30 & 72.60 & 72.35 & 1.018 & 1.007 \\
\hline
\end{tabular}

The control and sensitivity tests, Figure 8 , show the variation between repeated measurements on three subjects on three random days for the first $30 \mathrm{~min}$ and the hydration as the subjects consume different amounts of water. The standard deviation between average data points on the reported data for the three subjects who consented to participate and were used for control or baseline values ranged from $0.08 \mathrm{~dB}-0.18 \mathrm{~dB}$ for subject $\mathrm{D}, 0.47 \mathrm{~dB}-0.58 \mathrm{~dB}$ for subject $\mathrm{K}$ and $0.21 \mathrm{~dB}-0.22 \mathrm{~dB}$ for subject $\mathrm{L}$. The deviation from the baseline on the subjects after $100 \mathrm{~mL}$ intake are: subject $\mathrm{D}$ increased to $1.31 \mathrm{~dB}$, while subjects $\mathrm{K}$ and L increased by $2.75 \mathrm{~dB}$ and $0.77 \mathrm{~dB}$, respectively, after $250 \mathrm{~mL}$. As the amount of water consumed increased, hydration increased evidenced by the increase in signal gain. For example, subject $\mathrm{D}$ increased by $4.4 \mathrm{~dB}$ when the amount consumed increased from $100 \mathrm{~mL}$ to $250 \mathrm{~mL}$. After consuming $300 \mathrm{~mL}$, the change in signal gain from $250 \mathrm{~mL}$ to $300 \mathrm{~mL}$ on subjects $\mathrm{K}$ and $\mathrm{L}$ are $1.57 \mathrm{~dB}$ and $0.64 \mathrm{~dB}$, respectively. The measured attenuations after drink and after urination fall within baseline values, which were measured after fluid abstinence and before intake. The variation in the degree of measured attenuation between the three subjects is a result of individual specific body composition, initial hydration state and specific body metabolism.

Our simulation results show that, for maximum absorption of $100 \mathrm{~mL}$ within $20 \mathrm{~cm}$ channel length, the gain for different combinations of $\tau$ and $\theta$ are: $\tau=20$ and $\theta=0.6$, gain is $1.5 \mathrm{~dB}$, and when $\tau=80$ and $\theta=0.3$, gain is $1.71 \mathrm{~dB}$, and for $\tau=150$ and $\theta=0.2$, gain is $1.91 \mathrm{~dB}$. The theoretical dependences of the sensitivity are the individual metabolic function $\tau$, muscle-fat ratio, an equivalent of body mass index represented as $\theta$ and initial fluid level. Empirically, it is susceptible that a contributor to the sensitivity is height, which was not considered in the simulation. Others are subject specific endogenous processes or metabolism and initial body fluid states.

\section{Discussion}

\subsection{Hydration Measurement Techniques}

\subsubsection{Urine Colour Indices}

Urine color is attributed to the level of concentration of soluble waste substances in the urine. Higher concentration of soluble wastes may indicate a level of dehydration because the human body, in a healthy state, constantly tries to maintain homoeostatic water balance. Thus, with the loss of body water, urine colour changes in proportion to the level of dehydration, and darkens as dehydration increases or as the concentration of soluble waste increases in the urine [29]. Armstrong et al. [21] found that urine colour can, in some cases, indicate a person's hydration state because the changes in urine colour coincides with other techniques for measuring hydration such as plasma osmolality and urine specific gravity. However, there is no standard urine colour index to match a given magnitude of an individual hydration or dehydration state, especially when little changes occur that are not easily noticeable by observation. A 2015 report by Fortes et al. [12] showed that physical signs such as urine color and saliva are not sufficient for detecting changes in dehydration level. Our experiment uses the attenuation of a propagating electrical signal amplitude as a result of fluid absorbed through hydration or lost through dehydration to assess changes in body fluid level. Our sensitivity test showed that up to $1.30 \mathrm{~dB}$ gain can be detected in the arm when $100 \mathrm{~mL}$ of water is consumed, depending on the initial fluid requirement of an individual. 


\subsubsection{Change in Body Weight}

The human body mass contains $60 \%-70 \%$ water [27] with dynamic systems of gaining or losing water. Short term changes in body weight are attributed to loss or gain of body water because $1 \mathrm{~mL}$ of water has a mass of one gram [16]. Changes in body mass are often used to quantify water gain or loss in a clinical measurement. Consequently, we used the differences in body weight to deduce the amount of water retained in the body and to relate it with the changes in the intrabody signal passing through the body. We note that, as the body hydrates, only a proportion of the amount consumed comes to the arm where we measured. Our sensitivity test investigated the different amount of water required by each subject before it could be detected in the arm. Results show that the signal attenuation decreased as the body weight increased by the fluid consumed and increased as the body weight decreased due to loss of water (Figure 8).

\subsubsection{Refractometry}

With the loss of body water, urine specific gravity increases due to increase in the concentration of urinary waste products [30]. The concentration is determined by the amount of urinary waste per unit volume of urine. Urine specific gravity measures the ratio of the density of urine relative to the density of pure water. A specific gravity greater than 1 means the fluid is denser than water [22]. Urine specific gravity measurements usually range from 1.002 to 1.030 . Our results show that subjects with high SPG values usually had high hydration rates with the galvanic coupling method.

\subsection{Intrabody Signal Propagation Method}

Our proposed intrabody signal propagation method uses time varying changes in galvanic coupled signal amplitude to predict hydration rates. The decrease in attenuation (hydration) or increase (dehydration) during each observation matched the changes in the body weight recorded for all of the 20 subjects as well as the changes in the urine specific gravity and the visual observations on the urine colour.

We observed four distinct cases of human tissue hydration. We defined $W_{2}$ as Weight after urination and $W_{0}$ as weight before drink and grouped the cases as following:

Case 1: $W_{2}<W_{0}=$ Hyper hydration;

Case 2: $W_{2}=W_{0}=$ Optimal hydration;

Case 3: $W_{2}>W_{0}=$ Severe dehydrated;

Case 4: $W_{2}>W_{0}=$ Mild dehydration.

The graphs show that hydration started and ceased at different times per subject: $30 \%$ recorded hydration levels $10 \mathrm{~min}$ after drinking, while $25 \%$ recorded hydration levels at $5 \mathrm{~min}$ after drinking. Subjects with high SPG1 usually had higher rates of hydration, while subjects with very low SPG1 had lower rates of hydration. Thus, different individuals have different hydration rates and the specific gravity reading indicated an individual's initial dehydration state. Similarly, the amount of water consumed was too much for some subjects and just appropriate for others. These observations explain why the state of water balance is reached at different times and is dependent upon the initial body fluid level in each subject [15]. Figure 7 show that individuals with high BMI have longer time-dependent metabolic processes, and lower rates of hydration than people with low BMI, in line with our previous findings. The measured hydration rates lie within the range bounded by the mean value of the attenuation on an individual's baseline measurement. From Figure 8, the signal amplitude changed in proportion with the quantity of water absorbed by the tissues. Similarly, fluid consumption and losses caused changes in the body mass measurement in line with Equations (2) and (3). The variations in the signal amplitude were caused by the absorption of water by the tissues, which caused an increase due to hydration or reduction in body weight due to loss of water by evaporation, metabolism and urination. The signal amplitude increased more prominently as the volume of fluid consumed increased. For instance, within the first $5 \mathrm{~min}$, when the amount of water consumed 
by subject $\mathrm{D}$ increased from $100 \mathrm{~mL}$ to $250 \mathrm{~mL}$, the signal attenuation decreased from $-65.5 \mathrm{~dB}$ to $-61.9 \mathrm{~dB}$. The attenuation decreased as the amount of water consumed increased. This was reversed in the dehydration cycle measured after urination.

A review of bioimpedance and plasma osmolality methods indicates that intrabody methods, as shown in our experiment, are sensitive to detecting mild body fluid changes. Plasma osmolality measures the amount of osmoles (Osm) of solute per kilogram of solvent (osmol/ $\mathrm{kg}$ ) and is regarded as one of the best methods of estimating the level of dehydration in an individual [31]. The osmolality of blood increases with dehydration and decreases with increasing hydration. A problem with this method, however, is that it does not track body fluid changes quickly when fluid loss is below $3 \%$ of body mass [11,21]. This implies that, for a $70 \mathrm{~kg}$ adult, plasma osmolality could only detect changes in body fluid level until the water loss causes up to $2.1 \mathrm{~kg}$ decrease in body weight. Our technique is sensitive to $100 \mathrm{~mL}$ of fluid intake or $0.1 \mathrm{~kg}$ change in body weight due to hydration. Similarly, bioimpedance method tracks total body water from estimates of extracellular and intracellular fluid volumes [32]. However, although the bioimpedance method has been validated for estimating total body water [33], in 2007, Armstrong argued that bioelectrical impedance methods may not be accurate when the amount of water loss is less than $800-1000 \mathrm{~mL}$ [31]. Our sensitivity test showed that intrabody method could detect changes in body fluid level for as little as $100 \mathrm{~mL}$ of fluid intake or water loss as observed in subject D. Our sensitivity test suggests that the sensitivity increases with decrease in height. In addition, the magnitude of the signal attenuation from theoretical simulation changed from $-65.98 \mathrm{~dB}$ to $-63.27 \mathrm{~dB}$ for $\tau=80$ and $\theta=0.3$, similar to empirical measurements Figures 8 and 9. Our simulation results, in Figure 9, predicted a lowering of signal attenuation by $1.50 \mathrm{~dB}$ to as much as $1.91 \mathrm{~dB}$, depending on individual anthropometric ratio and body metabolism, when $100 \mathrm{~mL}$ is optimally absorbed in the arm. Our empirical measurements detected $1.31 \mathrm{~dB}$ on subject D, BMI $29.83 \mathrm{~kg} / \mathrm{m}^{2}$ and height $166 \mathrm{~cm}$. Thus, the empirical measurement is evidenced by simulation results. However, a challenge to the empirical measurements is that the majority of the participants were uncomfortable trying to remain still during the $20 \mathrm{~min}$ period in the first experiment, which was required to minimise movement artefacts and external effects. Thus, only three subjects consented to participate in the control and sensitivity test when it was extended to $30 \mathrm{~min}$ of measurements. In addition, we argue that the initial hydration state of the subjects with SPG readings should not be the gold standard [31] for assessing human body hydration state.

\section{Conclusions}

In this paper, we show that galvanic coupled intrabody signal propagation can be used to measure the rate of human body hydration with sensitivity as low as $100 \mathrm{~mL}$ of fluid intake or loss, and the system is non-invasive and hygienic. Our studies with 12 male and eight female volunteers show that the rate of hydration depended more on individual metabolic requirements, initial hydration level, and body mass index. Hydration rates are not constant but are affected by the immediate body physiological state and metabolic equilibrium, which, in turn, determines how long it takes to change from one fluid state to another. To use this technique, a baseline amplitude of the signal variations of an individual is required. This capacity makes it potentially applicable for monitoring changes in body fluid level, targeted body fluid disorder and the response of tissues when monitored for targeted fluid level variations. Using galvanic coupled intrabody communication means that the technology can be integrated into existing wearable devices in a cost effective way. In the future, we will further investigate the effects due to anthropometric parameters on the sensitivity.

Acknowledgments: This project is part of a PhD research project by Clement Ogugua Asogwa with no external funding beside the scholarship allowance received by the first author as a PhD candidate.

Author Contributions: Clement Ogugua Asogwa and Daniel TH Lai conceived and designed the experiments which was performed by the student (first author) and wrote the major draft; Patrick MacLaughlin, Stephen Collins and Daniel TH Lai assisted with the ethics application and review of the paper. 
Conflicts of Interest: The authors declare no conflict of interest.

\section{References}

1. Armstrong, L.E.; Pumerantz, A.C.; Fiala, K.A.; Roti, M.W.; Kavouras, S.A.; Casa, D.J.; Maresh, C.M. Human hydration indices: Acute and longitudinal reference values. Int. J. Sport Nutr. 2010, 20, 145-153.

2. Gandy, J. Water intake: Validity of population assessment and recommendations. Eur. J. Nutri. 2015, 54, 11-16.

3. Ibrahim, F.; Thio, T.H.G.; Faisal, T.; Neuman, M. The application of biomedical engineering techniques to the diagnosis and management of tropical diseases: A review. Sensors 2015, 15, 6947-6995.

4. Agostoni, C.V.; Bresson, J.L.; Fairweather-Tait, S. Scientific opinion on dietary reference values for water. EFSA J. 2010, 8, 1-47.

5. El-Sharkawy, A.M.; Watson, P.; Neal, K.R.; Ljungqvist, O.; Maughan, R.J.; Sahota, O.; Lobo, D.N. Hydration and outcome in older patients admitted to hospital (The HOOP prospective cohort study). Age Ageing 2015, 44, 943-947.

6. Schwan, H.P. Electrical properties of tissue and cell suspensions. Adv. Biol. Med. Phys. 1957, 5, 147-209.

7. Wabel, P.; Chamney, P.; Moissl, U.; Jirka, T. Importance of whole-body bioimpedance spectroscopy for the management of fluid balance. Blood Purif. 2009, 27, 75-80.

8. Rothlingshofer, L.; Ulbrich, M.; Hahne, S.; Leonhardt, S. Monitoring change of body fluid during physical exercise using bioimpedance spectroscopy and finite element simulations. J. Electr. Bioimped. 2011, 2, 79-85.

9. MirHojjat, S.; Kibret, B.; Lai, D.T.H.; Faulkner, M. A survey on intrabody communications for body area network applications. IEEE Trans. Biomed. Eng. 2013, 60, 2067-2079.

10. Mentes, J.C.; Wakefield, B.; Culp, K. Use of a Urine Color Chart to Monitor Hydration Status in Nursing Home Residents. Biol. Res. Nurs. 2006, 7, 173-203.

11. Francesconi, R.P.; Hubbard, R.W.; Szlyk, P.C.; Schnakenberg, D.; Carlson, D.; Leva, N.; Sils, I.; Hubbard, L.; Pease, V.; Young, J. Urinary and hematologic indexes of hypohydration J. Appl. Physiol. 1987, 62, 1271-1276.

12. Fortes, M.B.; Owen, J.A.; Raymond-Barker, P.; Bishop, C.; Elghenzai, S.; Oliver, S.J.; Walsh, N.P. Is this elderly patient dehydrated? Diagnostic accuracy of hydration assessment using physical signs, urine, and saliva markers. J. Am. Med. Dir. Assoc. 2015, 16, 221-228.

13. Gao, W.; Emaminejad, S.; Nyein, H.Y.Y.; Challa, S.; Chen, K.; Peck, A.; Fahad, H.M.; Ota, H.; Shiraki, H.; Kiriya, D.; et al. Fully integrated wearable sensor arrays for multiplexed in situ perspiration analysis. Nature 2016, 529, 509-514.

14. Kibret, B.; Seyedi, M.; Lai, D.T.H.; Faulkner, M. Investigation of Galvanic Coupled Intrabody Communication using Human Body Circuit Model. IEEE J. Biomed. Health Inform. 2014, 62, 1196-1206.

15. Asogwa, C.O.; Teshome, A.K.; Lai, D.T.H.; Collins, S.F. A Circuit Model of Real Time Human Body Hydration. IEEE Trans. Biomed. Eng. 2016, 63, 1239-1247

16. Lentner, C. Geigy scientific tables: Units of measurement, body fluids, composition of the body, nutrition. Basle Ciba-Geigy 1981, 1.

17. Kavouras, S. Assessing hydration status. Curr. Opin. Clin. Nutr. Metab. Care 2002, 5, 519-524.

18. Shirreffs, S.M. Markers of hydration status. Eur. J. Clin. Nutr. 2003, 57, S6-S9.

19. Mifflin, M.D.; St Jeor, S.T.; Hill, L.A.; Scott, B.J.; Daugherty, S.A.; Koh, Y.O. A new predictive equation for resting energy expenditure in healthy individuals. Am. J. Clin. Nutr. 1990, 51, 241-247.

20. Armstrong, L.E. Hydration assessment techniques. Nutr. Res. 2005, 63 (Suppl. 1), S40-S54.

21. Armstrong, L.E.; Soto, J.A.H.; Hacker, F.T., Jr.; Douglas, J.C.; Kavouras, S.A.; Maresh, C.M. Urinary indices during dehydration, exercise, and rehydration. Int. J. Sport Nutr. 1998, 8, 345-355.

22. Armstrong, L.E.; Maresh, C.M.; Castellani, J.W.; Bergeron, M.F.; Kenefick, R.W.; LaGasse, K.E.; Riebe, D. Urinary indices of hydration status. Int. J. Sport Nutr. 1994, 4, 265-279.

23. Asogwa, C.O.; Seyedi, M.; Lai, D.T. A preliminary investigation of human body composition using galvanically coupled signals. In Proceedings of the 9th International Conference on Body Area Networks, ICST (Institute for Computer Sciences, Social-Informatics and Telecommunications Engineering), London, UK, 29 September 2014; pp. 346-351. 
24. Peronnet, F.; Mignault, D.; Du Souich, P.; Vergne, S.; Le Bellego, L.; Jimenez, L.; Rabasa-Lhoret, R. Pharmacokinetic analysis of absorption, distribution and disappearance of ingested water labelled with D2O in humans. Eur. J. Appl. Physiol. 2012, 112, 2213-2222.

25. Wegmueller, M.S. Intra-body communication for biomedical seensor networks. Ph.D. Dissertation, ETH Zurich, Zurich, Switzerland, 2007.

26. Skelton, H. The storage of water by various tissues of the body. Arch. Intern. Med. 1927, 40, 140-152.

27. Jequier, E.; Constant, F. Water as an essential nutirent: the physiological basis of hydration. Eur. J. Clin. Nutr. 2009, 64, 115-123.

28. Bankir, L.; Bouby, N.; Trinh-Trang-Tan, M.M. The role of the kidney in the maintenance of water balance. Baillière Clin. Endoc. 1989, 3, 249-311.

29. Sands, J.M.; Layton, H.E. The physiology of urinary concentration: An update. Semin. Nephrol. 2009, 29, 178-195.

30. Oppliger, R.A.; Magnes, S.A.; Popowskim, L.A.; Gisolfi, C.V. Accuracy of urine specific gravity and osmolality as indicators of hydration status. Int. J. Sport Nutr. Exerc. Metab. 2005, 15, 236-251.

31. Armstrong, L.E. Assessing hydration status: the elusive gold standard. J. Am. Coll. Nutr. 2007, 26, 575S-584S.

32. Lukaski, H.C. Applications of Bioelectrical Impedance Analysis: A Critical Review. In In Vivo Body Composition Studies; Springer US: NY, USA, 1990; pp. 365-374.

33. Van Loan, M.D.; Withers, P.; Matthie, J.; Mayclin, P.L. Use of bioimpedance spectroscopy to determine extracellular fluid, intracellular fluid, total body water, and fat-free mass. In Human Body Composition; Springer US: NY, USA, 1993; pp. 67-70.

(C) 2016 by the authors; licensee MDPI, Basel, Switzerland. This article is an open access article distributed under the terms and conditions of the Creative Commons Attribution (CC-BY) license (http:/ / creativecommons.org/licenses/by/4.0/). 